\title{
CARDIO-RESPIRATORY DISORDERS AMONG SEWAGE WORKERS
}

\author{
By
}

\author{
Fahmy F.C., Mansour, T.A., Kamel, A.,
}

Moselhi, M. and Abbas, F.

From

Department of Occupational Health, High Institute of Public Health, Alexandia,Univiversity.

\begin{abstract}
:
Objective: The present study was designed to investigate cardio-respiratory disorders among sewage workers in Alexandria in order to suggest the suitable preventive measures for this sector.

Materials and Methods: This study was conducted on 67 male sewage workers and a control group of 60 non-exposed matched persons. All participants of the study were subjected to an interview using a pre-designed questionnaire and clinical general and systemic examinations as well as specific investigations including resting ECG, pulmonary function testing, plain chest X-ray and measurement of the level of sulf-hemoglobin.
\end{abstract}

Results: This study showed high smoking rate among sewage workers in comparison to controls $(\mathrm{p}=0.010)$. The resting ECG changes reported among the exposed workers in the present study were mainly left ventricular hypertrophy (LVH) and ischemic changes $(\mathrm{p}=0.027)$. Sulf-hemoglobin level was an independent determinant factor in multiple logistic regression models with $\mathrm{LVH}$ and ischemic changes as the dependent variables ( $\mathrm{p}=0.050$ and 0.000 respectively).

Significant reductions in percent predicted FVC and FEV1 among the exposed group versus controls ( $\mathrm{p}=0.000$ and 0.001 respectively), suggesting a restrictive pattern of impairment, were observed. Respiratory manifestations were the independent determinant for FVC and FEV1 in multiple regression analyses ( $\mathrm{p}=0.031 \& 0.05$ respectively).

Conclusion: Cardio-respiratory disorders among sewage workers should be considered in health surveillance of this sector with emphasis on antismoking measures. 
Key words: Sewage workers, cardio-respiratory disorders, left ventricular hypertrophy, ischemic changes, pulmonary functions, sulf-hemoglobin.

Abbreviations: BMI, body mass index; DBP, diastolic blood pressure; ECG, electrocardiogram; FEV1, forced expiratory volume in the first second; FVC, forced vital capacity; HR, heart rate; LVH, left ventricular hypertrophy; SBP, systolic blood pressure.

\section{Introduction:}

Sewage workers provide an essential service in the protection of public and environmental health. The working conditions of these workers have remained virtually unchanged for over a century. They are exposed to heavy physical exertion under adverse environmental conditions. These workers are also commonly exposed to gases like hydrogen disulfide, methane, ammonia and carbon monoxide (Tiwar, 2008). Previous studies have focused mainly on exposure to biological hazards and infections like hepatitis (Keeffe, 2004), leptospirosis (Amberkar et al., 2004), Helicobacter pylori (Friis et al., 1996) and dermatitis (Nethercott, 1981). Moreover, Wild et al. (2006), reported that cancer mortality seems to increase with employment as a sewage worker.

Exposure to hydrogen sulfide (H2S) is the most characteristic exposure for sewage workers. It has an irritant action even at low concentrations and an asphyxiant effect in massive exposure. It interacts with hemoglobin to produce sulf-hemoglobin which is normally near zero level. Its presence re- flects the degree of exposure level (WHO, 1981).

Cardiovascular effects of $\mathrm{H} 2 \mathrm{~S}$ have been reported after acute exposure to induce ECG changes similar to myocardial infarction that was reversible in some cases (Audeau et al., 1985). There was contradiction in the literature as regard chronic cardiovascular disorders due to exposure to H2S. In a recent review by Tiwari (2008), it was stated that ischemic changes are observed after long term exposure, as well as arrhythmias and hemodynamic instability in the form of elevated blood pressure among sewage workers. On the other hand, this was not reported in some other studies (Rylander, 1999). It seems that the exact nature of cardiovascular affection is still unclear.

Thorn et al. (2002), reported that respiratory manifestations are common among this sector of workers. Nethercott and Holness (1988), observed changes in pulmonary functions among sewage workers. However, there are some discrepancies between different studies about the nature of the respiratory dysfunction whether is it re- 
strictive or obstructive. Richardson (1995), studied exposure to hydrogen sulfide in sewer workers and found that the ratio of forced expiratory volume in first second of the forced vital capacity (FEV1/FVC) was lower in sewer workers with high $\mathrm{H} 2 \mathrm{~S}$ exposure.

The present study was designed to investigate Cardio-respiratory disorders among sewage workers in Alexandria especially in relation to $\mathrm{H} 2 \mathrm{~S}$ exposure in order to suggest the suitable preventive measures for this sector.

\section{Subjects and Methods:}

A cross sectional study was designed to involve workers in Alexandria sewage disposal stations. The study included 67 randomly selected male sewage workers within the periodic medical examination program. A control group of 60 non exposed persons matched as regards to age, sex and socioeconomic status to the exposed group was selected. All participants of the study were subjected to an interview using a predesigned questionnaire including personal, occupational and medical histories with emphasis on respiratory and cardiovascular conditions as well as smoking habit. Clinical general and systemic examinations, measurement of heart rate and arterial blood pressure was done ac- cording to the European guidelines (ESH and ESC, 2007). Height, weight and body mass index (BMI) were measured according to standard methods (Rose, et al. 1982). Resting standard 12 lead ECG was done for each participant and was analyzed to define cases of left ventricular hypertrophy $(\mathrm{LVH})$, changes suggestive of ischemia and other abnormal findings according to the standard criteria (Fisch, 1994).Respiratory symptoms were classified according to Medical Research Council guidelines (1965). Pulmonary function testing according to American Thoracic Society Association (1987), was conducted to measure forced vital capacity (FVC) and Forced expiratory volume (FEV1). Results were expressed as percent of predicted values. Also the ratio FEV1/FVC was calculated. Plain chest $\mathrm{X}$-ray postero-anterior view was performed for each participant in study and the results were assessed by a consultant occupational chest disease physician. A venous un-clotted blood sample was collected for each participant to measure the level of sulf-hemoglobin as a parameter of $\mathrm{H} 2 \mathrm{~S}$ exposure (NIOSH, 1977).

Data was analyzed using SPSS (Statistical package for social sciences) version 15. Comparison of means of quantitative variables between two groups was done by independent $\mathrm{t}$-test. Chi-square test was 
used for categorical variables and Fisher exact test was done when numbers were small. Multivariate analyses for dependent qualitative variables were done by logistic regression; meanwhile, dependent quantitative variables were tested by multiple regressions. Models were constructed to determine the independent variables in each one. The level of significance for $p$ value was considered at 0.05 .

\section{Results:}

The mean age for the exposed sewage workers and for controls were 44.5 and 44.2 years respectively, with no significant difference. The mean duration of exposure of the studied sewage workers was 16.6 years. There was no significant difference between exposed workers and controls as regards height, weight and BMI. (Table 1)

The percent of smokers was significantly higher among the exposed group $73.0 \%$ than the controls $52.0 \%(\mathrm{p}=0.010)$. Also, the smoking index was significantly higher among the exposed group than the controls $(p=0.032)$. Although there was no significant difference between the exposed and control groups in cardiovascular symptoms; yet, dyspnoea and atypical chest pain were highly reported in $27.0 \%$ and $9.0 \%$ among the exposed group compared to about $8.0 \%$ and $3.0 \%$ in the con- trols respectively. Anginal chest pain and palpitation were almost equally reported among the exposed workers and their controls. Respiratory manifestations were significantly more prevalent among exposed workers than the controls ( $p=0.017)$. It was found that chronic bronchitis and chronic asthmatic bronchitis were the most common respiratory conditions among sewage workers in comparison to controls ( $24 \%$ and $10.5 \%$ vs $6.7 \%$ and $3.3 \%$ respectively). (Table 2)

There was no significant differences between exposed workers and controls in systolic (SBP) and diastolic blood pressure (DBP); while, the exposed workers showed significantly lower heart rate than controls $(p=0.015)$.

As regard pulmonary function tests, the study revealed that the percent of predicted values for FVC and FEV1 was significantly lower among exposed workers than controls $(\mathrm{p}=0.000$ and $\mathrm{p}=0.001$ respectively). However, there was no significant difference in the ratio FEV1/FVC.

The increase in percent of sulf-hemoglobin among exposed workers versus controls was highly significant $(\mathrm{p}=0.000)$. (Table3)

Resting ECG findings were more significantly observed among the exposed work- 
ers than controls $(p=0.027)$. Left ventricular hypertrophy (LVH) was found in $18.0 \%$ of exposed workers as compared to $5.0 \%$ in the controls. Also ischemic changes were diagnosed in $13.5 \%$ of exposed workers in comparison to $6.6 \%$ of controls. No significant difference was found in chest $\mathrm{X}$ ray findings between exposed workers and controls. (Table 4)

Multivariate analysis was done with logistic regression considering $\mathrm{LVH}$ as the dependent variable. It showed that the level of sulf-hemoglobin was the only independent variable approaching significance in this model $(\mathrm{p}=0.050)$. Also, multivariate logistic regression with ECG ischemic changes as the dependent variable, showed that SBP, DBP and sulf-hemoglobin were the independently significant variables in the model $(p=0.006,0.031$ and 0.000 respectively). (Table5)

Multiple regression model was constructed considering FVC as the dependent variable. It showed that smoking index, presence of respiratory manifestations and duration of exposure were the independently significant variables in the model. $(p=0.024,0.031$ and 0.013 respectively). Another multiple regression model was done for FEV1 as the dependent variable. It showed that presence of respiratory manifestations was the only independent variable approaching significance in this model $(p=0.050)$. (Table6) 
Table 1: Characteristics of the study population.

\begin{tabular}{|l|c|c|c|c|c|c|}
\hline \multirow{2}{*}{\multicolumn{1}{|c|}{ Characteristics }} & \multicolumn{2}{|c|}{ Exposed } & \multicolumn{2}{c|}{ Control } & \multirow{2}{*}{$\mathrm{t}$} & \multirow{2}{*}{$\mathrm{P}$} \\
\cline { 2 - 5 } & Mean & S.D. & Mean & S.D. & & \\
\hline Age (years) & 44.5 & 7.97 & 44.2 & 7.74 & 0.039 & 0.844 \\
Duration of exposure (years) & 16.6 & 7.39 & - & - & - & - \\
Height $(\mathrm{cm})$ & 172.0 & 7.47 & 172.3 & 6.47 & 0.084 & 0.772 \\
Weight $(\mathrm{kg})$ & 78.8 & 5.00 & 80.9 & 7.76 & 3.222 & 0.075 \\
Body Mass Index $\left(\mathrm{kg} / \mathrm{m}^{2}\right)$ & 26.7 & 1.84 & 27.2 & 2.01 & 0.761 & 0.138 \\
\hline
\end{tabular}

* Significant at 0.05 level.

Table 2: Smoking and cardio-respiratory manifestations among the studied population.

\begin{tabular}{|l|c|c|c|c|c|c|}
\hline \multirow{2}{*}{ Variables } & \multicolumn{2}{|c|}{$\begin{array}{c}\text { Exposed } \\
(\mathrm{n}=67)\end{array}$} & \multicolumn{2}{c|}{$\begin{array}{c}\text { Control } \\
(\mathrm{n}=60)\end{array}$} & \multirow{2}{*}{$\mathrm{X}^{2}$} & $\mathrm{p}$ \\
\cline { 2 - 5 } & No. & $\%$ & No. & $\%$ & & \\
\hline Smoking & 49 & 73.1 & 31 & 51.7 & 6.258 & $0.010^{*}$ \\
Smoking index $^{\circledR}$ & 298.8 & 315.66 & 189.7 & 240.53 & 4.711 & $0.032^{*}$ \\
Cardiovascular symptoms: & & & & & & \\
Atypical chest pain & 6 & 9.0 & 2 & 3.3 & 8.65 & 0.070 \\
Anginal pain & 3 & 4.5 & 2 & 3.3 & & \\
Palpitation & 3 & 4.5 & 2 & 3.3 & & \\
Dyspnea & 18 & 27.0 & 5 & 8.3 & & \\
$\quad$ Respiratory manifestations: & 4 & 6.0 & 6 & 10.0 & 5.61 & $0.017^{*}$ \\
Cough & 16 & 24.0 & 4 & 6.7 & & \\
Chronic Bronchitis & 7 & 10.5 & 2 & 3.3 & & \\
Chronic asthmatic Bronchitis & & & & & & \\
\hline
\end{tabular}

*Significant at 0.05 level.

@ Cigarettes /day . Years of smoking, Mean \pm S.D., t-test for difference. 
Table 3: Cardio-respiratory measurements and sulf-hemoglobin level among the studied population.

\begin{tabular}{|c|c|c|c|c|c|c|}
\hline \multirow{2}{*}{ Measurements } & \multicolumn{2}{|c|}{ Exposed } & \multicolumn{2}{|c|}{ Control } & \multirow[b]{2}{*}{$\mathrm{t}$} & \multirow[b]{2}{*}{$\mathrm{p}$} \\
\hline & Mean & SD & Mean & SD & & \\
\hline HR (beat/minute) & 69.9 & 4.27 & 71.5 & 3.31 & 6.050 & $0.015^{*}$ \\
\hline $\mathrm{SBP}(\mathrm{mmHg})$ & 120.5 & 13.26 & 122.7 & 12.37 & 0.882 & 0.350 \\
\hline $\mathrm{DBP}(\mathrm{mmHg})$ & 78.4 & 8.58 & 79.4 & 7.43 & 0.472 & 0.493 \\
\hline FVC (\% of predicted) & 84.8 & 15.03 & 94.5 & 7.05 & 21.108 & $0.000^{*}$ \\
\hline $\mathrm{FEV}_{1}(\%$ of predicted $)$ & 84.0 & 20.98 & 93.6 & 8.08 & 11.085 & $0.001^{*}$ \\
\hline $\mathrm{FEV}_{1} / \mathrm{FVC}(\%)$ & 83.1 & 9.87 & 84.9 & 11.69 & 0.861 & 0.355 \\
\hline Sulf-hemoglobin (\%) & 0.37 & 0.27 & 0.09 & 0.10 & 24.509 & $0.000^{*}$ \\
\hline
\end{tabular}

* Significant at 0.05 level.

HR, heart rate; SBP, systolic blood pressure; DBP, diastolic blood pressure; FVC, forced vital capacity; FEV1, forced expiratory volume in the first second.

Table 4: Resting ECG and chest X-ray findings among the studied population.

\begin{tabular}{|l|c|c|c|c|c|c|}
\hline \multirow{2}{*}{ Investigations } & \multicolumn{2}{|c|}{$\begin{array}{c}\text { Exposed } \\
(\mathrm{n}=67)\end{array}$} & \multicolumn{2}{c|}{$\begin{array}{c}\text { Control } \\
(\mathrm{n}=60)\end{array}$} & \multirow{2}{*}{$\mathrm{X}^{2}$} & $\mathrm{p}$ \\
\cline { 2 - 5 } & No. & $\%$ & No. & $\%$ & & \\
\hline Reting ECG findings: & 12 & 18.0 & 3 & 5.0 & 7.21 & $0.027^{*}$ \\
LVH $^{\mathrm{a}}$ & 9 & 13.5 & 4 & 6.6 & \\
Ischemic changes & & & & & & \\
Chest X-ray findings: & 5 & 7.5 & 2 & 3.3 & Fisher & 0.33 \\
Increased broncho-vascular & & & & & $\begin{array}{c}\text { exact } \\
\text { test }\end{array}$ \\
markings & & & & & \\
\hline
\end{tabular}

* Significant at 0.05 level.

a Six cases out of exposed and all cases of controls were hypertensives.

$\mathrm{b}$ Five cases of the exposed group and two cases of controls gave past history of CAD. 
Fahmy F.C. et al.,

Table 5: Multiple Logistic Regression Analyses.

\begin{tabular}{|l|c|c|c|c|c|}
\hline \multirow{2}{*}{ Models } & \multicolumn{2}{|c|}{$\begin{array}{c}\text { Unstandardized } \\
\text { Coefficient }\end{array}$} & $\begin{array}{c}\text { standardized } \\
\text { Coefficient }\end{array}$ & \multirow{2}{*}{$\mathrm{t}$} & $\mathrm{p}$ \\
\cline { 2 - 4 } & $\mathrm{B}$ & $\begin{array}{c}\text { Std. } \\
\text { Error }\end{array}$ & Beta & & \\
\cline { 2 - 5 } LVH model: & & & & & \\
Constant & 3.501 & 2.533 & & \\
SBP & 0.015 & 0.015 & -0.145 & -1.007 & 0.316 \\
DPB & 0.004 & 0.24 & 0.025 & 0.171 & 0.865 \\
HR & -0.26 & 0.030 & -0.076 & -0.858 & 0.392 \\
Sulf-hemoglobin & 1.029 & 0.519 & -0.176 & 1.983 & $0.050^{*}$ \\
\hline ECG ischemic changes model: & 0.199 & 0.539 & & 0.370 & 0.712 \\
Constant & -0.007 & 0.003 & -0.367 & -0.2779 & $0.006^{*}$ \\
SBP & 0.009 & 0.004 & 0.290 & 2.169 & $0.032^{*}$ \\
DBP & 0.004 & 0.005 & 0.058 & 0.715 & 0.476 \\
HR & -0.014 & 0.011 & -0.108 & -1.344 & 0.182 \\
BMI & 0.379 & 0.092 & 0.339 & 4.125 & $0.000^{*}$ \\
Sulf-hemoglobin & 0.064 & 0.044 & 0.121 & 1.458 & 0.148 \\
Smoking & & & & \\
\hline
\end{tabular}

* Significant at 0.05 level. 
Table 6: Multiple regression analyses.

\begin{tabular}{|c|c|c|c|c|c|}
\hline \multirow[t]{2}{*}{ Models } & \multicolumn{2}{|c|}{$\begin{array}{c}\text { Unstandardized } \\
\text { Coefficient }\end{array}$} & \multirow{2}{*}{$\begin{array}{c}\begin{array}{c}\text { standardized } \\
\text { Coefficient }\end{array} \\
\text { Beta }\end{array}$} & \multirow{2}{*}{$\mathrm{t}$} & \multirow{2}{*}{$\mathrm{p}$} \\
\hline & $\mathrm{B}$ & Std. Error & & & \\
\hline \multicolumn{6}{|l|}{ FVC model: } \\
\hline Constant & 106.611 & 14.851 & & 7.178 & $0.000^{*}$ \\
\hline Age & -0.184 & 0.139 & -0.112 & -1.319 & 0.190 \\
\hline Smoking index & -0.009 & 0.004 & -0.193 & -2.289 & $0.024^{*}$ \\
\hline BMI & -0.080 & 0.527 & -0.012 & -0.151 & 0.880 \\
\hline Respiratory symptoms & -2.351 & 1.079 & -0.186 & -2.179 & $0.031^{*}$ \\
\hline Sulf-hemoglobin & -1.990 & 5.029 & -0.036 & -0.396 & 0.693 \\
\hline Duration of exposure & -0.319 & 0.127 & -0.245 & -2.523 & $0.013^{*}$ \\
\hline \multicolumn{6}{|l|}{ FEV 1 model: } \\
\hline Constant & 105.116 & 20.162 & & 5.214 & 0.000 \\
\hline Age & -0.287 & 0.189 & -0.133 & -1.521 & 0.131 \\
\hline Smoking index & -0.008 & 0.005 & -0.144 & -1.648 & 0.102 \\
\hline BMI & 0.160 & 0.716 & 0.018 & 0.224 & 0.823 \\
\hline Respiratory symptoms & -2.907 & 1.465 & -0.175 & -1.984 & $0.050^{*}$ \\
\hline Sulf-hemoglobin & -5.215 & 6.827 & -0.764 & -0.764 & 0.446 \\
\hline Duration of exposure & -0.318 & 0.172 & -0.186 & -1.850 & 0.67 \\
\hline
\end{tabular}

* Significant at 0.05 level. 


\section{Discussion:}

Sewage workers are at great risk in their peculiar work environment since they are exposed to different occupational hazards including physical, chemical, biological, mechanical and psychosocial factors. The most striking characteristic of the current occupational group is the presence of high smoking rate among them with considerable number of heavy smokers as reflected from their high smoking index. This characteristic was also reported by Wild et al. (2006), in a recent survey of sewage workers in Paris. They reported high prevalence rate of smoking and alcohol drinking among this sector. They explained that this is due to the belief of workers that smoking may ameliorate bad smell of their working condition, which is going with our result.

The cardiovascular changes reported among the exposed workers in the present study were mainly LVH and ischemic changes. Although, there were no significant differences in mean values of systolic and diastolic blood pressure of the exposed workers and controls; yet, LVH was reported among $18 \%$ of sewage workers. Only $50 \%$ of them were hypertensives; meanwhile, all controls with LVH (5\%) were hypertensives. It is well known that hypertension is the most common cause of LVH (Mathews et al., 1987). This may be attributed to the possible hemodynamic instability with episodes of elevated blood pressure resulting from exposure to H2S (Tiwari, 2008 and WHO, 1982). Another explanation is the presence of heavy physical exertion with high load. This was abundantly reported among athletes and in some occupations as a form of response, in some individuals, to static loading (Maron, 2003). Also, bradycardia may be a form of heart rate affection due to $\mathrm{H} 2 \mathrm{~S}$ exposure and/or response to heavy physical loading. This observation should be considered in the future studies on basis of larger sample size.

Ischemic changes in resting ECG were reported among about 14\% of sewage workers in comparison to about $7 \%$ only of controls. This finding is going with some reports among chronically exposed sewage workers (Audeau et al., 1985 and WHO, 1981). In multivariate logistic regression model SBP, DBP and sulf-hemoglobin were the independent variables influencing the occurrence of the current ischemic changes. It is known that both systolic and diastolic blood pressure are conventional cardiovascular risk factors. However, the independent association between sulf-hemoglobin and ischemic cardiac changes that was found in this study may be unique observation. Sulf-hemoglobin is a parameter of exposure to $\mathrm{H} 2 \mathrm{~S}$ with its irritant 
characteristics; however, it may be associated with many other noxious chemicals that could be present in sewage waste, augmenting a possible inflammatory vascular reaction (Blanchard et al., 2004). This is going with the current theory explaining coronary artery disease as an inflammatory process induced by endothelial injury (Hanson, 2005).

Respiratory system affection was found among sewage workers in this study in terms of significant reduction in both FVC and FEV1 without change in their ratio. This pattern of changes in pulmonary functions is suggestive of a restrictive type of respiratory impairment. Respiratory manifestations were independently influencing reductions in both FVC and FEV1. Smoking index and duration of exposure were additional independent factors reducing FVC only. This peculiar pattern may be explained by exposure to endotoxins and air born bacteria inducing a possible immunological reaction resulting in a form of allergic alveolitis. Zuskin et al., 1990 reported similar findings. On the other hand, Richardson (1995), claim a possible obstructive pattern of impairment in pulmonary functions among sewage workers. Another report demonstrated reduction in forced expiratory flow rate at $25-50 \%$ of forced expiration suggesting small air ways obstruction
(Zuskin et al., 1993). Smoking is a well established respiratory hazard that was highly reported among sewage workers and independently reducing FVC. Therefore, the possible etiologic biological agent, the specific immunological responses and the effect of duration of exposure are still needed to be investigated in future studies.

\section{Conclusion and recommendations:}

This study pointed out to the occurrence of possible cardio-respiratory disorders among sewage workers in the form of $\mathrm{LVH}$, resting ECG ischemic changes and restrictive pattern of impairment in pulmonary functions. Therefore, it is recommended that:

- Individuals with cardio-respiratory disorders should be excluded in preplacement medical examination from working as sewage workers.

- Sulf-hemoglobin measurement, resting ECG and pulmonary function tests should be included in periodic medical examination for this sector of workers.

- The working conditions of sewage workers should be improved with mechanization of the process especially as regard H2S exposure. Physical activity among these workers should be optimized to limit undue static loading and to promote dynamic activity. 
- Health education and smoking cessation programs should be emphasized.

- Further studies are needed to investigate more details about cardio-respiratory disorders in this group of workers.

\section{References}

1. Ambekar, A.N., Bharadwaj, R.S., Joshi, S.A., Kagal, A.S. and Bal, A.M. (2004). "Sero surveillance of leptospirosis among sewer workers in Pune.” Indian J Public Health. 48: 27-29.

2. American Thoracic Society Statement. (1987). "Standardization of spirometry-update." A Review Respir Dis. 136: 1285-1289.

3. Audeau, F.M., Gnanaharan, C. and Davey, K. (1985). "Hydrogen sulphide poisoning: Associated with pelt processing." N Z Med J. 98:145147.

4. Blanchard, M., Teil, M.J., Ollivon, D., Legenti, L. and Chevreuil, M. (2004). "Polycyclic aromatic hydrocarbons and poly chlorobiphenyl in waste water and sewage sludges from the Paris area (France)." Environmental Res. 95: 184197.

5. ESH and ESC. (2007). The Task Force for Management of Arterial Hypertension of the European Society of Hypertension and of The European Society of Cardiology. 2007 Guidelines for the management of arterial hypertension. Eur Heart J. doi: 10. 1093/eurheartJ/ehm236

6. Fisch, C. (1994). "Electrocardiography and vectorcardiography.” In: Heart Diseases. (E. Braunwold, ed) 4th ed. Philadelfia, pp. 116-155.

7. Friis, L., Engstrand, L. and Edling, C. (1996). "Prevalence of Helicobacter pylori infection among sewage workers." Scand J Work Environ Health. 22: 364-368.
8. Hanson, G.K. (2005). "Inflammation, atherosclerosis and coronary artery disease." N Engl J Med. 352: 1685-1695.

9. Keeffe, E.B. (2004). "Occupational risk for hepatitis A: A literature-based analysis." J Clin Gastroenterol. 38: 440-448.

10. Maron, B.J. (2003). "Sudden death in young athletes.” N Engl J Med. 349: 1064-1075.

11. Matthews, K.A., Cottington, E.M., Talbott, E., Kuller, L.H. and Siegel J.M. (1987). "Stressful work conditions and diastolic blood pressure among blue collar factory workers." Am J Epidemiol. 126 (2): 280-291.

12. Medical Research Council. (1965). "Report on the etiology of chronic bronchitis: Definition and classification of chronic bronchitis for clinical and epidemiological purpose." Lancet. 1: 775-779.

13. NIOSH. (1977). "Criteria for a recommended standard: Occupational exposure to hydrogen sulfide." DHEW (National Institute for Occupational Safety and Health) publ.77-158.

14. Nethercott, J.R. (1981). "Airborne irritant contact dermatitis due to sewage sludge." J Occup Med. 23: 771-774.

15. Nethercott, J.R. and Holness, D.L. (1988). "Health status of a group of sewage treatment workers in Toronto, Canada." Am Ind Hyg Assoc J. 49: 346-350.

16. Richardson, D.B. (1995). "Respiratory effects of chronic hydrogen sulfide exposure." Am J Ind Med. 28: 99-108.

17. Rose, G.A., Blackburn, H., Gillum, R.T. and Prineos, R.J. (1982). Cardiovascular Survey Methods. 2nd edition, WHO, Geneva.

18. Rylander, R. (1999). "Health effects among workers in sewage treatment plants." Occup Environ Med. 56: 354-357. 
19. Thorn, J., Beijer, L. and Rylander, R. (2002). "Work related symptoms among sewage workers: A nationwide survey in Sweden." Occup Environ Med. 59: 562-566.

20. Tiwari, R.R. (2008). "Occupational health hazards in sewage and sanitary workers." IJOEM. 12 (3): 112-115.

21. WHO. (1981). Hydrogen sulfide: Environmental Health Criteria 19, Geneva, World Health Organization.
22. Wild, P., Ambroise, D., Benbrik, E., Tiberguent, A. and Massin, N. (2006). "Mortality among Paris sewage workers." Occup Environ Med. 63(3): 163-172

23. Zuskin, E., Mustajbegovic, J., Lukenda-Simovic, D. and Ivankovic, D. (1990). "Respiratory symptoms and ventilatory capacity of sewage canal workers." Lijec Vjesn. 112: 353-357.

24. Zuskin,E, Mustajbegovic, J. and Schachter, E.N. (1993). "Respiratory functions in sewage workers.” Am J Ind Med. 23: 751-761. 